\title{
South Korea surrenders to creationist demands
}

\section{Publishers set to remove examples of evolution from high-school textbooks.}

\section{BY SOO BIN PARK IN SEOUL}

$\mathrm{M}$ ention creationism, and many scientists think of the United States, where efforts to limit the teaching of evolution have made headway in a couple of states ${ }^{1}$. But the successes are modest compared with those in South Korea, where the anti-evolution sentiment seems to be winning its battle with mainstream science.

A petition to remove references to evolution from high-school textbooks claimed victory last month after the Ministry of Education, Science and Technology (MEST) revealed that many of the publishers would produce revised editions that exclude examples of the evolution of the horse or of avian ancestor Archaeopteryx. The move has alarmed biologists, who say that they were not consulted. "The ministry just sent the petition out to the publishing companies and let them judge," says Dayk Jang, an evolutionary scientist at Seoul National University.

The campaign was led by the Society for Textbook Revise (STR), which aims to delete the "error" of evolution from textbooks to "correct" students' views of the world, according to the society's website. The society says that its members include professors of biology and high-school science teachers.

The STR is also campaigning to remove content about "the evolution of humans" and "the adaptation of finch beaks based on habitat and mode of sustenance", a reference to one of the most famous observations in Charles Darwin's On the Origin of Species. To back its campaign, the group highlights recent discoveries that Archaeopteryx is one of many feathered dinosaurs, and not necessarily an ancestor of all birds $^{2}$. Exploiting such debates over the lineage of species "is a typical strategy of creation scientists to attack the teaching of evolution itself", says Joonghwan Jeon, an evolutionary psychologist at Kyung Hee University in Yongin.

The STR is an independent offshoot of the Korea Association for Creation Research (KACR), according to KACR spokesman Jungyeol Han. Thanks in part to the KACR's efforts, creation science - which seeks to provide evidence in support of the creation myth described in the Book of Genesis - has had a growing influence in South Korea, although the STR itself has distanced itself from such doctrines. In early 2008, the KACR scored a hit with a successful exhibition at Seoul Land, "The ministry
just sent the
petition out to
the publishing
companies and
let them judge." one of the country's leading amusement parks. According to the group, the exhibition attracted more than 116,000 visitors in three months, and the park is now in talks to create a year-long exhibition.

Even the nation's leading science institute the Korea Advanced Institute of Science and Technology — has a creation science display on campus. "The exhibition was set up by scientists who believed in creation science back in 1993," says Gab-duk Jang, a pastor of the campus church. The institute also has a thriving Research Association for Creation Science, run by professors and students, he adds.

\section{ANTIPATHY TO EVOLUTION}

In a 2009 survey conducted for the South Korean documentary The Era of God and Darwin, almost one-third of the respondents didn't believe in evolution. Of those, $41 \%$ said that there was insufficient scientific evidence to support it; $39 \%$ said that it contradicted their religious beliefs; and 17\% did not understand the theory. The numbers approach those in the
United States, where a survey by the research firm Gallup has shown that around $40 \%$ of Americans do not believe that humans evolved from less advanced forms of life.

The roots of the South Korean antipathy to evolution are unclear, although Jeon suggests that they are partly "due to strong Christianity in the country". About half of South Korea's citizens practice a religion, mostly split between Christianity and Buddhism.

However, a survey of trainee teachers in the country concluded that religious belief was not a strong determinant of their acceptance of evolution $^{3}$. It also found that $40 \%$ of biology teachers agreed with the statement that "much of the scientific community doubts if evolution occurs"; and half disagreed that "modern humans are the product of evolutionary processes".

Until now, says Dayk Jang, the scientific community has done little to combat the antievolution sentiment. "The biggest problem is that there are only $5-10$ evolutionary scientists in the country who teach the theory of evolution in undergraduate and graduate schools," he says. Having seen the fierce debates over evolution in the United States, he adds, some scientists also worry that engaging with creationists might give creationist views more credibility among the public.

Silence is not the answer, says Dayk Jang. He is now organizing a group of experts, including evolutionary scientists and theologians who believe in evolution, to counter the SRT's campaign by working to improve the teaching of evolution in the classroom, and in broader public life..

1. Thompson, H. Nature http://dx.doi.org/10.1038/ nature.2012.10423 (2012).

2. Xu, X., You, H., Du, K. \& Han, F. Nature $475,465-470$ (2011).

3. Kim, S. Y. \& Nehm, R. H. Int. J. Sci. Edu. 33, 197-227 (2011).

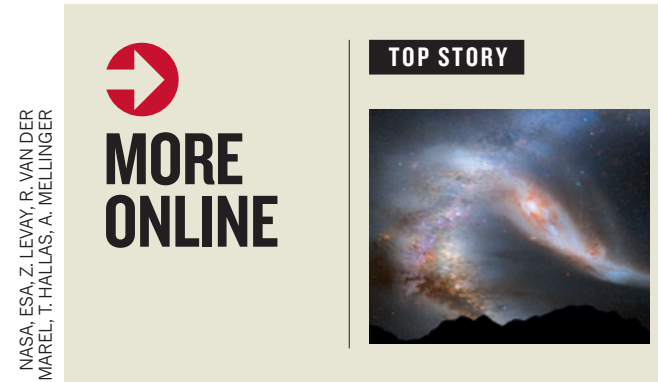

Andromeda on collision course with the Milky Way go.nature.com/ djnfcz

\section{MORE NEWS}

- Slow progress on Indonesian deforestation ban go.nature.com/whmkp8 - Mysterious radiation burst recorded in tree rings go.nature.com/2n56y6 - US agencies tackle dearth of evidence on painkillers go.nature.com/ rladj2

\section{VIDEO}

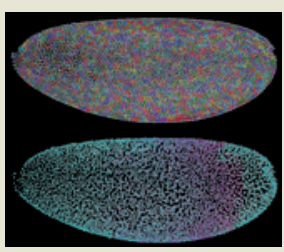

Watching an embryo as it develops cell-by-cell go.nature.com/ bywonh 